\title{
Влияние кислотно-основных свойств допантов, вводимых в мембраны МФ-4СК, на характеристики потенциометрических сенсоров в растворах никотиновой кислоты
}

\author{
(C) 2020 Хабтемариам Г.3. ${ }^{1}$, Паршина А.В. ${ }^{1,}$, Колганова Т.С. ${ }^{1}$, \\ Сафронова Е.Ю. ${ }^{2}$, Бобрешова О.В. ${ }^{1}$ \\ ${ }^{1}$ Воронежский государственный университет, Воронеж \\ ${ }^{2}$ Институт общей и неорганической химии им. Н.С. Курнакова РАН, Москва
}

Поступила в редакцию 08.04.2020 г.

DOI: $10.17308 /$ sorpchrom.2020.20/2873

Никотиновая кислота (3-пиридинкарбоновая кислота) относится к витаминам группы В, а по отношению к окружающей среде является поллютантом. Для ее определения в пищевых, фармацевтических и физиологических средах известны методики масс-спектрометрии и хроматографии с различными способами детектирования, а также электрохимические сенсоры. В вольтамперометрических сенсорах для определения никотиновой кислоты используют различные гибридные материалы. Однако использование подобных материалов в потенциометрических сенсорах для определения никотиновой кислоты в литературе не описано.

В данной работе исследована возможность использования гибридных материалов на основе перфторированной сульфокатионообменной мембраны МФ-4СК и поверхностно модифицированных наночастиц оксидов циркония и кремния для потенциометрического определения никотиновой кислоты в водных растворах. Показано, что варьирование кислотно-основных свойств и объемной доли допантов, вводимых в мембрану, оказывает существенное влияние на перекрестную чувствительность ПД-сенсоров к ионам никотиновой кислоты и гидроксония. Присутствие в мембране 3 мас.\% оксида кремния с 15 мол.\% 3-аминопропила на поверхности снижает в 2 раза чувствительность ПДсенсоров к мешающим ионам гидроксония и в 6 раз пределы обнаружения никотиновой кислоты по сравнению с таковыми для немодифицированного образца. Также снижение мешающего влияния ионов гидроксония на отклик ПД-сенсора и уменьшение предела обнаружения никотиновой кислоты достигаются при использовании мембраны, содержащей 5 мас.\% оксида кремния с 3-пропилсульфокислотными группами. ПД-сенсоры на основе выбранных мембран характеризуются достаточно высокой чувствительностью к никотиновой кислоте (30.8 и 29.3 мВ/pc). Данные образцы могут быть использованы для разработки сенсорных систем для определения никотиновой кислоты в водных растворах и фармацевтических препаратах.

Ключевые слова: ПД-сенсоры, перфторированные сульфокатионообменные мембраны, гибридные материалы, оксид циркония, оксид кремния, модификация поверхности, никотиновая кислота.

\section{Введение}

Никотиновая кислота (3-пиридинкарбоновая кислота) является витаминам группы В, а по отношению к окружающей среде является поллютантом $[1,2]$. Для ее определения в пищевых, фармацевтических и физиологических средах известны методики масс-спектрометрии $[3,4]$ и хроматографии с различными способами детектирования [5-7], а также электрохимические сенсоры [8-12]. Авторами [8] для опре- 
деления никотиновой кислоты предложен твердоконтактный потенциометрический сенсор на основе пластифицированной поливинилхлоридной мембраны и ионных пар протонированного аналита и аниона борорганического соединения. В вольтамперометрических сенсорах для определения никотиновой кислоты используют различные гибридные материалы: графитовый пастовый электрод, модифицированный восстановленным оксидом графена и молекулярно импринтированными полимерами [9], пастовый электрод на основе смеси парафина, нанокомпозита углеродных нанотрубок (УНТ) и $\mathrm{La}^{-\mathrm{TiO}_{2}}$ [10], стеклоуглеродный электрод, модифицированный УНТ [11]. Кроме того, гибридные материалы [13], а также металлы [14], оксиды [15-17], соли [18] и полимеры [19] исследованы в качестве твердофазных сорбентов никотиновой кислоты и катализаторов ее превращений. Однако использование подобных материалов в потенциометрических сенсорах для определения никотиновой кислоты в литературе не описано.

В данной работе исследована возможность использования гибридных материалов на основе перфторированной сульфокатионообменной мембраны МФ-4СК и поверхностно модифицированных наночастиц оксидов циркония и кремния для потенциометрического определения никотиновой кислоты в водных растворах. Поскольку ПД-сенсоры не содержат селективно взаимодействующих с аналитом компонентов, модификация должна способствовать увеличению концентрации ионов никотиновой кислоты и снижению концентрации мешающих ионов гидроксония в мембране при ее контакте с анализируемым раствором. Никотиновая кислота содержит в своей структуре атом азота в пиридиновом цикле и карбоксильную группу (рис. 1), что обеспечивает ее амфолитические свойства, поэтому в качестве допантов были выбраны оксиды с сульфо- и аминосодержащими фрагментами. Предполагали, что помимо присутствия в мембране реакционных центров с различными кислотноосновными свойствами, на сорбцию определяемых и мешающих ионов будет влиять изменение размеров внутрипорового пространства вследствие взаимодействия поверхности допанта и стенок пор [20, 21].<smiles>O=C([O-])c1ccc[nH+]c1</smiles>

Рис. 1. Структурная формула цвиттер-иона никотиновой кислоты

Целью работы явилось исследование влияния кислотно-основных свойств и объемной доли допантов, вводимых в мембрану МФ-4СК, на характеристики ПДсенсоров в растворах никотиновой кислоты.

\section{Экспериментальная часть}

Объекты исследования. Исследовали водные растворы никотиновой кислоты с концентрациями от $1.0 \cdot 10^{-4}$ до $1.0 \cdot 10^{-1} \mathrm{M}$ (pH 3.42-4.74). Для их приготовления использовали никотиновую кислоту ( $\geq 99.5 \%$, Sigma-Aldrich) и бидистиллированную воду с сопротивлением 18 МОм. Диаграмма распределения ионных форм никотиновой кислоты $\left(\mathrm{NA}^{+}, \mathrm{NA}^{ \pm}, \mathrm{NA}^{-}\right)$в зависимости от $\mathrm{pH}$ среды построена с учетом значений констант диссоциации функциональных групп $\mathrm{pK}_{\mathrm{a}}(-\mathrm{COOH})=2.08$, $\mathrm{pK}_{\mathrm{b}}\left(\equiv \mathrm{NH}^{+}\right)=4.82$, представленных в [22] (рис. 2). В исследуемом диапазоне $\mathrm{pH}$ никотиновая кислота находится в цвиттер-ионной форме. 


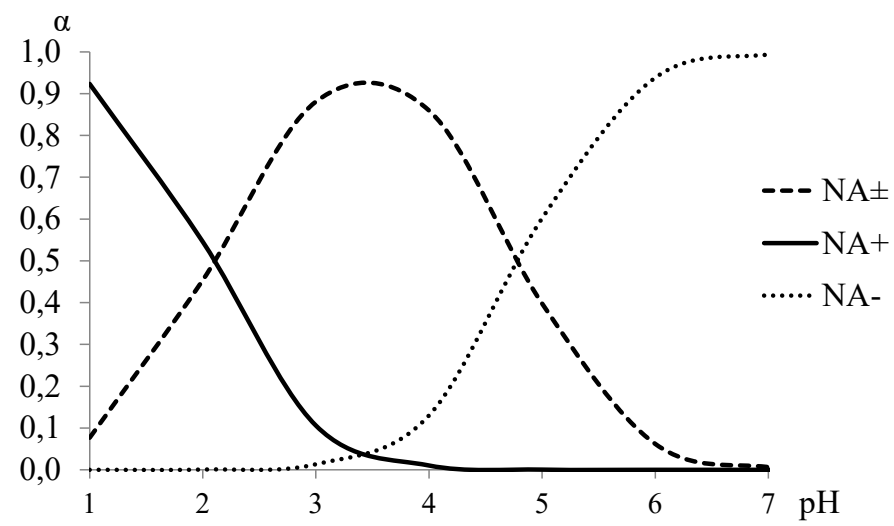

Рис. 2. Диаграмма распределения ионных форм никотиновой кислоты в диапазоне рН 1-7

В качестве материалов ПД-сенсоров исследовали перфторированные сульфокатионообменные мембраны МФ-4СК, содержащие наночастицы оксидов циркония $\mathrm{ZrO}_{2}$ и кремния $\mathrm{SiO}_{2}$, поверхностно модифицированные сульфогруппами, 3-пропилсульфокислотными группами и 3-аминопропилом (R). Материалы $\mathrm{MФ-4CK}+\mathrm{ZrO}_{2}-\mathrm{SO}_{3} \mathrm{H}$ и МФ-4CK $+\mathrm{SiO}_{2}-\left(\mathrm{CH}_{2}\right)_{3}-\mathrm{SO}_{3} \mathrm{H}$ были получены отливкой из раствора полимера, содержащего навески допантов с заданной концентрацией (3 и 5\% от массы мембраны), по методике, описанной в [20]. Материалы $\mathrm{MФ-4CK+3} \mathrm{мас. \%} \mathrm{SiO}_{2}\left(-\left(\mathrm{CH}_{2}\right)_{3}-\mathrm{NH}_{2}\right)$, были получены отливкой из раствора полимера в присутствии расчетного количества 3-аминопропилтриметоксисилана для дальнейшего получения допанта по методике, описанной в [21]. Концентрация 3-аминопропила на поверхности оксида составляла 5, 10 и 15 мол.\% от его количества. Материалы были получены таким образом, что допант содержала только $1 / 2$ часть пленки, конец которой контактировал с исследуемым раствором. Часть пленки, контактирующая с раствором сравнения ПД-сенсора, модифицирована не была. Это обеспечивало близость составов раствора внутри мембраны и раствора сравнения ПД-сенсора для нивелирования потенциала Доннана на их границе.

В ПД-сенсорах использовали мембраны в $\mathrm{K}^{+}$-форме для снижения влияния на величину и стабильность отклика ионов гидроксония, которые имеют высокую подвижность и могут участвовать как в ионообменных, так и в протолитических реакциях в фазах раствора и мембраны. Практические преимущества использования $\mathrm{K}^{+}$формы мембран обусловлены легким процессом «регенерации» материалов посредством ионного обмена. Кроме того, в этом случае в качестве раствора сравнения для ПД-сенсора используется $1 \mathrm{M}$ раствор $\mathrm{KCl}$, что обеспечивает наименьшие значения диффузионного потенциала жидкостного соединения на границе раствора сравнения ПД-сенсора с внутренним раствором хлоридсеребряного электрода сравнения.

После длительного использования в ПД-сенсорах (до 3 месяцев) мембраны «регенирировали» путем выдерживания в $2 \mathrm{M}$ раствором $\mathrm{KCl}$ на 72 ч с последующим промыванием бидистиллированной водой. Между сериями повторных измерений ( 100 измерений) мембраны выдерживали в $0.1 \mathrm{M}$ растворе $\mathrm{KCl}$ в течение 30 мин при постоянном перемешивании. Между измерениями мембраны помещали в бидистиллированной воду.

Методы исследования. Схема ячейки для оценки откликов системы ПДсенсоров на основе мембран разного состава подробно описана в [23]. Ячейка включала два корпуса из непроводящего материала, набор мембран разного состава, хлоридсеребряные электроды и многоканальный потенциометр. Мембраны одним концом погружали в общую секцию с исследуемым раствором, а другим концом - в от- 
дельные секции с раствором сравнения. Гибридные мембраны погружали в исследуемый раствор концом модифицированной части образца. Хлоридсеребряный электрод (ЭСр-10103, ООО «Эконикс-эксперт»), подключенный к входу многоканального потенциометра для электрода сравнения, погружали в исследуемый раствор, а хлоридсеребряные электроды (ЭСр-10103, ООО «Сенсорные Системы»), подключенные к измерительным входам, - в раствор сравнения. Напряжение нескольких цепей (1) измеряли по очереди с помощью многоканального аналого-цифрового преобразователя. Одновременно с этим измеряли $\mathrm{pH}$ исследуемого раствора с применением стеклянного электрода (ЭС-10301/4, ООО «Эконикс-эксперт»).

$\mathrm{Ag}|\mathrm{AgCl}, 1 \mathrm{M} \mathrm{KCl}|$ мембрана| исследуемый раствор $\mid$ нас. $\mathrm{KCl}, \mathrm{AgCl} \mid \mathrm{Ag}$

Для оценки воспроизводимости отклика ПД-сенсора в исследуемых растворах определяли дисперсию отклика $\left(\mathrm{s}^{2}, \mathrm{MB}^{2}\right)$. Оценку стабильности откликов ПДсенсоров выполняли на основе результатов хронопотенциометрических измерений в течение 1 ч. Для определения времени отклика сенсора ( $t_{\text {response, }}$ мин) сравнивали разброс значений отклика в течение времени измерения с разбросом значений при дублировании эксперимента.

Расчёт коэффициентов градуировочных уравнений методом многомерного регрессионного анализа выполняли с учетом влияния на отклик ПД-сенсоров концентрации ионов никотиновой кислоты и гидроксония:

$$
\Delta \varphi_{\mathrm{D}}=b_{0}+b_{1} p N A+b_{2} p H,
$$

где $\Delta \varphi_{D}$ - величина отклика ПД-сенсора, $\mathrm{MB} ; p N A$ - отрицательный десятичный логарифм молярной концентрации ионов никотиновой кислоты; $b_{0}-$ свободный член градуировочного уравнения, мВ; $b_{i}-$ коэффициенты чувствительности ПД-сенсора к соответствующим ионам, $\mathrm{MB} / \mathrm{p} c$.

Для выявления возможных систематических погрешностей и доказательства правильности выбора градуировочного уравнения оценивали его адекватность по $F$ критерию Фишера. Значимость коэффициентов уравнения оценивали по $t$-критерию Стьюдента. Корреляцию между значениями отрицательного десятичного логарифма молярной концентрации ионов в градуировочных растворах (для оценки обусловленности уравнений) оценивали по r-критерию.

Предел обнаружения $\left(\mathrm{c}_{\min }\right)$ аналита оценивали по правилу «три сигма» как его минимальную концентрацию, при которой величина отклика сенсора в растворе $\left(\Delta \varphi_{\min }\right)$ отличается от величины отклика в фоне $\left(\Delta \varphi_{\text {фон }}\right)$ более, чем на утроенное стандартное отклонение отклика в фоне ( $\left.\mathrm{s}_{\text {фон, }} \mathrm{MB}\right)$. В качестве фона использовали бидистиллированную воду.

\section{Обсуждение результатов}

ПД-сенсоры на основе исходной и гибридных мембран характеризуются относительно низкими значениями времени установления отклика ( $\mathrm{t}_{\text {response }}<1$ мин) и дисперсии отклика $\left(\mathrm{s}^{2}=27-67 \mathrm{MB}^{2}\right)$ в растворах никотиновой кислоты в диапазоне концентраций от $1.0 \cdot 10^{-4}$ до $1.0 \cdot 10^{-1} \mathrm{M}$. Градуировочные характеристики ПДсенсоров не изменяются в течение длительного времени использования вследствие того, что при переводе мембран в $\mathrm{K}^{+}$-форму их регенерация происходит полностью.

ПД-сенсоры на основе исходного и модифицированных образцов имеют высокую чувствительность к никотиновой кислоте (рис. 3,4$)$ несмотря на то, что она находится в растворе в цвиттер-ионной форме. В ряде исследований показано, что вытеснение ионов гидроксила из фазы катионообменной мембраны (доннановское исключение) приводит к снижению $\mathrm{pH}$ внутрипорового раствора примерно на 2 единицы по сравнению с рН внешнего раствора. В соответствии с диаграммой распре- 
деления ионных форм (рис. 2) никотиновая кислота в фазе мембраны, контактирующей с раствором с $\mathrm{pH} 3.42-4.74$, должна находиться преимущественно в катионной форме за счет протолиза аминогруппы в пиридиновом цикле.

Для образцов, содержащих оксиды с протонодонорными и протоноакцепторными группами, наблюдается противоположный вид зависимостей чувствительности ПД-сенсоров к ионам никотиновой кислоты и гидроксония от объемной доли допанта (рис. 3,4$)$. Это связано с различным влиянием присутствия и концентрации соответствующих допантов на объем внутрипорового пространства мембран и доступность реакционных центров для объемных ионов аналита.

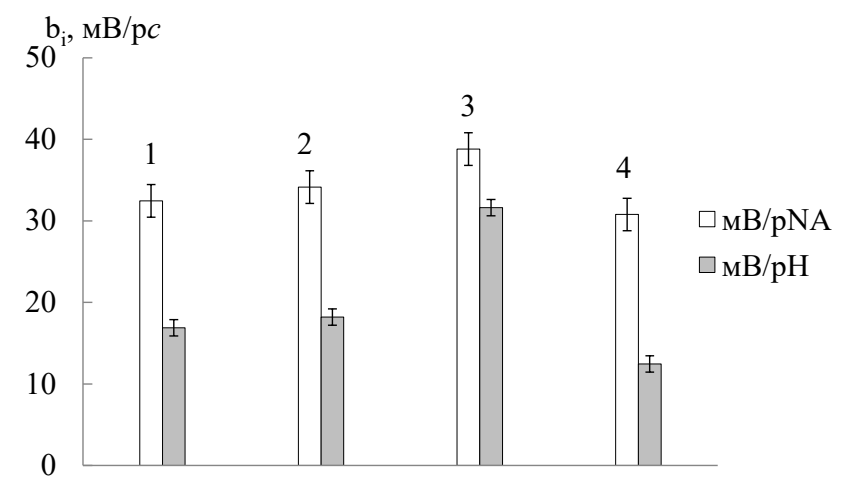

Рис. 3. Коэффициенты чувствительности ПД-сенсоров к ионам никотиновой кислоты и $\mathrm{H}_{3} \mathrm{O}^{+}$. Образцы расположены в порядке увеличения объемной доли допанта в мембране МФ-4СК: 1 - исходный образец;

$$
\begin{gathered}
2-\mathrm{M \Phi}-4 \mathrm{CK}+3 \text { мас. } \% \mathrm{ZrO}_{2}-\mathrm{SO}_{3} \mathrm{H} ; 3-\mathrm{M \Phi}-4 \mathrm{CK}+3 \text { мac. } \% \mathrm{SiO}_{2}\left(\mathrm{CH}_{2}\right)_{3} \mathrm{SO}_{3} \mathrm{H} ; \\
4-\mathrm{M} \Phi-4 \mathrm{CK}+5 \text { мас. } \% \mathrm{SiO}_{2}\left(\mathrm{CH}_{2}\right)_{3} \mathrm{SO}_{3} \mathrm{H}
\end{gathered}
$$

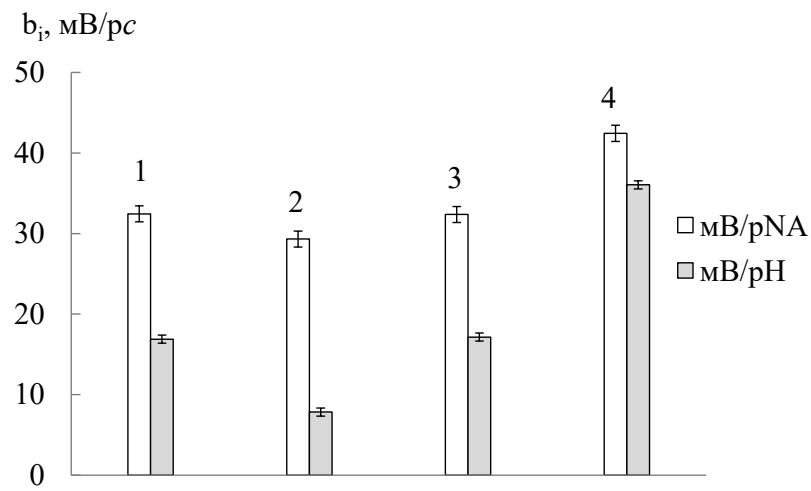

Рис. 4. Коэффициенты чувствительности ПД-сенсоров к ионам никотиновой кислоты и $\mathrm{H}_{3} \mathrm{O}^{+}$. Образцы расположены в порядке увеличения объемной доли допанта в мембране МФ-4СК: 1 - исходный образец; 2 - МФ-4СК + 3 мас.\% $\mathrm{SiO}_{2}$

(5 мол.\% - $\left.\left(\mathrm{CH}_{2}\right)_{3}-\mathrm{NH}_{2}\right) ; 3-\mathrm{M \Phi}-4 \mathrm{CK}+3$ мас.\% $\mathrm{SiO}_{2}\left(10\right.$ мол.\% $\left.-\left(\mathrm{CH}_{2}\right)_{3}-\mathrm{NH}_{2}\right)$;

$$
4 \text { - МФ-4СК + } 3 \text { мас.\% } \mathrm{SiO}_{2}\left(15 \text { мол. } \%-\left(\mathrm{CH}_{2}\right)_{3}-\mathrm{NH}_{2}\right)
$$

В ряду образцов МФ-4СК, содержащих 3 мас.\% $\mathrm{ZrO}_{2}-\mathrm{SO}_{3} \mathrm{H}$, 3 мас.\% $\mathrm{SiO}_{2}\left(\mathrm{CH}_{2}\right)_{3} \mathrm{SO}_{3} \mathrm{H}$ и 5 мас.\% $\mathrm{SiO}_{2}\left(\mathrm{CH}_{2}\right)_{3} \mathrm{SO}_{3} \mathrm{H}$ возрастает объемная доля допанта, а диффузионная проницаемость мембран снижается [20]. При этом влагосодержание данных образцов ниже исходного на 3-5 \% [20]. Это обусловлено тем, что частицы допанта располагаются в центре пор и вытесняют часть «электронейтрального» раствора. При достаточно высоком содержании допанта (3-5 мас.\%) электростатического отталкивания стенок пор от одноименно заряженной поверхности допанта и осмотического давления, создаваемого ионами, образующимися при диссоциации функциональных групп, оказывается недостаточно для дальнейшего растя- 
жения стенок пор и увеличения влагосодержания [20]. В связи с этим первоначальный рост чувствительности ПД-сенсоров к ионам никотиновой кислоты и гидроксония (для образцов МФ-4СК, содержащих 3 мас. $\% \mathrm{ZrO}_{2}-\mathrm{SO}_{3} \mathrm{H}$ и 3 мас.\% $\mathrm{SiO}_{2}\left(\mathrm{CH}_{2}\right)_{3} \mathrm{SO}_{3} \mathrm{H}$, рис. 3), по-видимому, обусловлен возрастанием концентрации противоионов в мембране из-за увеличения числа функциональных групп и снижения объема внутрипорового раствора. Для образца МФ-4СК, содержащего 5 мас.\% $\mathrm{SiO}_{2}\left(\mathrm{CH}_{2}\right)_{3} \mathrm{SO}_{3} \mathrm{H}$, диффузионная проницаемость в 3.5 раза ниже, чем исходной мембраны МФ-4СК, что, по-видимому, ограничивает сорбцию объемных ионов никотиновой кислоты и чувствительность ПД-сенсоров к ним снижается. При этом более резкое снижение чувствительности ПД-сенсоров к ионам гидроксония (в 1.4 раза по сравнению с исходной мембраной) может быть связано с исключением их из ионного обмена из-за образования связей между аминогруппами ионов никотиновой кислоты и сульфогруппами на стенках пор и поверхности допанта.

Согласно [21] равновесные и транспортные свойства мембран МФ-4СК, содержащих $\mathrm{SiO}_{2}\left(-\left(\mathrm{CH}_{2}\right)_{3}-\mathrm{NH}_{2}\right)$, изменяются немонотонно с увеличением объема вводимых частиц. Аминогруппы на поверхности допанта способны к образованию связей с сульфогруппами мембраны, что подтверждается снижением ионообменной емкости модифицированных мембран (0.65-0.74 ммоль/г) по сравнению с исходной (0.93 ммоль/г) [21]. Наиболее эффективно такое взаимодействие реализуется для образца с наименьшей концентрацией поверхностных групп допанта (5 мол.\%), что проявляется в снижении его диффузионной проницаемости [21]. Для этого же образца наблюдается снижение (в 2 раза) чувствительности ПД-сенсора к мешающим ионам гидроксония в растворах никотиновой кислоты. При этом чувствительность к ионам аналита также несколько снижается, но остается достаточно высокой $(29.3 \pm 1.1 \mathrm{mB} / \mathrm{pc})$. По-видимому, при малом объеме внутри пор никотиновая кислота, имеющая третичную аминогруппу в пиридиновом цикле и карбоксильную группу, способна взаимодействовать с сульфогруппами мембраны и аминогруппами допанта по типу хелатного эффекта. При увеличении количества групп 3-аминопропила на поверхности допанта влагосодержание снижается на 4.4\%, а диффузионная проницаемость мембран возрастает в 5 раз относительно исходных значений, что связано с присутствием объемных частиц в центре пор [21]. Возможно, это облегчает сорбцию объемных ионов аналита и, в то же время, доступность фиксированных групп мембраны для мешающих ионов, что обусловливает возрастание чувствительности ПДсенсоров к ним.

Таким образом, наибольшее отношение значений коэффициентов чувствительности ПД-сенсоров к определяемым и мешающим ионам было получено для двух образцов МФ-4СК + 5 мас.\% $\mathrm{SiO}_{2}\left(\mathrm{CH}_{2}\right)_{3} \mathrm{SO}_{3} \mathrm{H}$ и МФ-4СК + 3 мас.\% $\mathrm{SiO}_{2}\left(5\right.$ мол.\% - $\left.\left(\mathrm{CH}_{2}\right)_{3}-\mathrm{NH}_{2}\right)$. Для ПД-сенсоров на основе данных образцов, а также на основе исходного образца была выполнена оценка пределов обнаружения (табл. 1)

Таблица 1. Пределы обнаружения ионов никотиновой кислоты с помощью ПД-сенсоров

\begin{tabular}{|c|c|c|c|}
\hline Мембрана & $\left(\Delta \varphi_{\text {D }}\right)_{\text {фон }}, \mathrm{MB}$ & $\mathrm{s}_{\text {фон }}, \mathrm{MB}$ & $c_{\text {min }}\left(\mathrm{NA}^{ \pm}\right), \mathrm{M}$ \\
\hline МФ-4СК & $214 \pm 6$ & 10 & $8.4 \cdot 10^{-8}$ \\
\hline $\mathrm{MФ-4СК} \mathrm{+} \mathrm{5} \mathrm{мас. \%} \mathrm{SiO}_{2}\left(\mathrm{CH}_{2}\right)_{3} \mathrm{SO}_{3} \mathrm{H}$ & $215 \pm 7$ & 11 & $1.8 \cdot 10^{-8}$ \\
\hline МФ-4СК + 3 мас.\% $\mathrm{SiO}_{2}\left(5\right.$ мол.\% $\left.-\left(\mathrm{CH}_{2}\right)_{3}-\mathrm{NH}_{2}\right)$ & $239 \pm 6$ & 8 & $1.3 \cdot 10^{-8}$ \\
\hline
\end{tabular}

Хабтемариам и др. / Сорбционные и хроматографические процессы. 2020. Т. 20. № 3. С. 369-377 
ПД-сенсоры на основе выбранных модифицированных образцов обеспечивают в 5-6 раз более низкие значения пределов обнаружения ионов никотиновой кислоты в водных растворах по сравнению с исходным образцом (табл. 1).

\section{Заключение}

Исследованы характеристики ПД-сенсоров на основе перфторированных сульфокатионообменных мембран МФ-4СК, содержащих поверхностно модифицированные сульфо- и аминосодержащими фрагментами оксиды циркония и кремния, в водных растворах никотиновой кислоты. ПД-сенсоры на основе исследуемых мембран имеют высокую чувствительность к никотиновой кислоте из-за ее перехода в катионную форму в фазе мембраны. Варьирование кислотно-основных свойств и объемной доли допантов, вводимых в мембрану, оказывает существенное влияние на перекрестную чувствительность ПД-сенсоров к ионам никотиновой кислоты и гидроксония. Присутствие в мембране 3 мас.\% оксида кремния с 15 мол.\% 3 -аминопропила на поверхности снижает в 2 раза чувствительность ПД-сенсоров к мешающим ионам гидроксония и в 6 раз пределы обнаружения никотиновой кислоты по сравнению с таковыми для немодифицированного образца. Также снижение мешающего влияния ионов гидроксония на отклик ПД-сенсора и уменьшение предела обнаружения никотиновой кислоты достигаются при использовании мембраны, содержащей 5 мас.\% оксида кремния с 3-пропилсульфокислотными группами. Данные образцы могут быть использованы для разработки сенсорных систем для определения никотиновой кислоты в водных растворах и фармацевтических препаратах.

Исследование выполнено при финансовой поддержке РФФИ

и Правительства Воронежской области в рамках научного проекта № 19-48-363008.

\section{Список литературы}

1. Padoley K.V., Mudliar S.N., Pandey R.A. // Bioresource technology. 2008. Vol. 99. No $10 . \quad$ pp. 4029-4043. DOI: 10.1016/j.biortech.2007.01.047.

2. Gupta V.K., Saleh T.A. // Environmental science and pollution research. 2013. Vol. 20. No 5. pp. 2828-2843. DOI: 10.1007/s11356013-1524-1.

3. Shin H., Kim B., Lee J. // Food chemistry. 2013. Vol. 138. No 2-3. pp. 1109-1115. DOI: 10.1016/j.foodchem.2012.11.046.

4. Shrivas K., Patel D.K. // Spectrochimica Acta Part A: Molecular and Biomolecular Spectroscopy. 2011. Vol. 78. No 1. pp. 253-257. DOI: 10.1016/j.saa.2010.10.003.

5. Santos J.R., Rangel António O.S.S. // Food chemistry. 2015. Vol. 187. pp. 152-158. DOI: 10.1016/j.foodchem.2015.04.093.

6. Wang L.H. // Analytical Letters. 2016. Vol. 49. No 10. pp. 1467-1479. DOI: 10.1080/00032719.2015.1113422.

7. Parham H., Zargar B., Khoshnam F. // Food analytical methods. 2015. Vol. 8. No 9. pp. 2235-2242. DOI: 10.1007/s12161-0150095-9.

8. Alizadeh T., Amjadi S. // Microchimica Acta. 2017. Vol. 184. No 8. pp. 2687-2695. DOI: $10.1007 / \mathrm{s} 00604-017-2296-\mathrm{y}$.

9. Wu J., Liu H., Lin Z. // Sensors. 2008. Vol. 8. No 11. pp. 7085-7096. DOI: 10.3390/s8117085.

10. Шаофан Л. // Электрохимия. 2006. Т. 42. №. 2. C. 190-195.

11. Stoica A.I., Kleber C., Viñas C., Teixidor F. // Electrochimica Acta. 2013. Vol. 113. pp. 94-98. DOI: 10.1016/j.electacta.2013.09.025.

12. Wang X., Yang N., Wan Q. // Electrochimica acta. 2006. V. 52. No. 1. P. 361-368. DOI: 10.1016/j.electacta.2006.05.014.

13. Mohammad A., Amin A., Naushad M., El-Desoky G.E. // Journal of thermal analysis and calorimetry. 2013. V. 111. No. 1. P. 831838. DOI: 10.1007/s10973-011-2169-2.

14. Tian H.W., Li W.H., Wang D.P., Hou B.R. // Acta Physico-Chimica Sinica. 2012. V. 
28. No. 1. P. 137-145. DOI: 10.3866/PKU.WHXB201228137.

15. Власова Н.Н., Головкова Л.П., Стукалина Н.Г. // Коллоидный журнал. 2015. Т. 77. № 4.4 C. 433-433. DOI: $10.7868 / \mathrm{S} 0023291215040205$.

16. Penta N.K., Peethala B.C., Amanapu H.P., Melman A. et al. // Colloids and Surfaces A: Physicochemical and Engineering Aspects. 2013. Vol. 429. pp. 67-73. DOI: 10.1016/j.colsurfa.2013.03.046.

17. Schnadt J., O'shea J.N., Patthey L., Schiessling J. et al. // Surface science. 2003. Vol. 544. No 1. pp. 74-86. DOI: 10.1016/j.susc.2003.08.013.

18. Dancu A.C., Barabas R., Bogya E.S. // Central European Journal of Chemistry. 2011. Vol. 9. No 4. pp. 660-669. DOI: 10.2478/s11532-011-0057-z.

19. Альтшулер Г.Н., Остапова Е.В., Малышенко Н.В., Альтшулер О.Г. // Известия
Академии наук. Серия химическая. 2017. № 10. C. 1854-1859.

20. Паршина А.В., Денисова Т.С., Сафронова Е.Ю., Караванова Ю.А. и др. // Журнал аналитической химии. 2017. Т. 72. №. 12. С. 1104-1112.

DOI: $10.7868 / \mathrm{S} 0044450217120088$.

21. Михеев А.Г., Сафронова Е.Ю., Ярославцев А.Б. // Мембраны и мембранные технологии. 2013. Т. 3. № 2. С. 93-99. DOI: $10.1134 / \mathrm{S} 2218117213020090$.

22. Niazi M. S. K., Mollin J. // Bulletin of the Chemical Society of Japan. 1987. Vol. 60. No 7. pp. 2605-2610. DOI: https://doi.org/10.1246/bcsj.60.2605

23. Safronova E., Parshina A., Kolganova T., Bobreshova O. et al. // Journal of Electroanalytical Chemistry. 2018. Vol. 816. pp. 21-29. DOI: 10.1016/j.jelechem. 2018.03.028.

\title{
The influence of acid-base properties of dopants incorpo- rated into the MF-4SC membranes on the characteristics of potentiometric sensors in nicotinic acid solutions
}

\author{
(C) 2020 Habtemariam G.Z. ${ }^{1}$, Parshina A.V. ${ }^{1}$, Kolganova T.S. ${ }^{1}$, \\ Safronova E.Yu. ${ }^{2}$, Bobreshova O.V. ${ }^{1}$ \\ ${ }^{1}$ Voronezh State University, Voronezh \\ ${ }^{2}$ Kurnakov Institute of General and Inorganic Chemistry RAS, Moscow
}

\begin{abstract}
Nicotinic acid (3-pyridinecarboxylic acid) is a B vitamin, and it is a pollutant with respect to the environment. Mass spectrometry and chromatography techniques with various detection methods, as well as electrochemical sensors are known for its determination in food, pharmaceutical and physiological environments. A variety of hybrid materials are used in voltammetry sensors for the determination of nicotinic acid. However, the use of such materials in potentiometric sensors for determining nicotinic acid is not described in the literature.

In this work, the possibility of using of hybrid materials based on the perfluorosulfonic acid cation exchange MF-4SC membrane and surface-modified nanoparticles of zirconia and silica for potentiometric determination of nicotinic acid in aqueous solutions was investigated. It was shown that varying the acid-base properties and the volume fraction of the dopants incorporated into the membrane have a significant effect on the cross sensitivity of DP-sensors (sensors with Donnan potential as analytical signal) to nicotinic acid and hydroxonium ions. The presence of $3 \mathrm{wt} . \%$ silica with $15 \mathrm{~mol} . \% 3$-aminopropyl on the surface in the membrane reduces the sensitivity of DP-sensors to interfering hydroxonium ions by 2 times and the detection limits of nicotinic acid by 6 times compared to those for an unmodified sample. Also, a decrease in the interfering effect of hydroxonium ions on the response of the DP-sensor and a decrease in the detection limit of nicotinic acid are achieved by using a membrane containing $5 \mathrm{wt} . \%$ silica with 3-propyl sulfonic acid groups. DPsensors based on selected membranes are characterized by a high sensitivity to nicotinic acid (30.8 and 29.3 $\mathrm{mV} / \mathrm{pc}$ ). These samples can be used to develop sensory systems for determination nicotinic acid in aqueous solutions and pharmaceuticals.
\end{abstract}

Keywords: DP-sensor, perfluorosulfonic acid membranes, hybrid materials, zirconia, silica, surface modification, nicotinic acid.

\section{References}

1. Padoley K.V., Mudliar S.N., Pandey R.A., pp. 4029-4043. Bioresource technology, 2008, Vol. 99, No 10, 10.1016/j.biortech.2007.01.047. 
2. Gupta V.K., Saleh T.A., Environmental science and pollution research, 2013, Vol. 20, No 5, pp. 2828-2843. DOI: 10.1007/s11356013-1524-1.

3. Shin H., Kim B., Lee J., Food chemistry, 2013, Vol. 138, No 2-3, pp. 1109-1115. DOI: 10.1016/j.foodchem.2012.11.046.

4. Shrivas K., Patel D.K., Spectrochimica Acta Part A: Molecular and Biomolecular Spectroscopy, 2011, Vol. 78, No 1, pp. 253-257. DOI: 10.1016/j.saa.2010.10.003.

5. Santos J.R., Rangel António O.S.S., Food chemistry, 2015, Vol. 187, pp. 152-158. DOI: 10.1016/j.foodchem.2015.04.093.

6. Wang L.H., Analytical Letters, 2016, Vol. 49, No 10, pp. 1467-1479. DOI: 10.1080/00032719.2015.1113422.

7. Parham H., Zargar B., Khoshnam F., Food analytical methods, 2015, Vol. 8, No 9, pp. 2235-2242. DOI: 10.1007/s12161-015-0095-9.

8. Stoica A.I., Kleber C., Viñas C., Teixidor F., Electrochimica Acta, 2013, Vol. 113, pp. 9498. DOI: 10.1016/j.electacta.2013.09.025.

9. Alizadeh T., Amjadi S., Microchimica Acta, 2017, Vol. 184, No 8, pp. 2687-2695. DOI: 10.1007/s00604-017-2296-y.

10.Wu J., Liu H., Lin Z., Sensors, 2008, Vol. 8, No 11, pp. 7085-7096. DOI: $10.3390 / \mathrm{s} 8117085$.

11.Sh. Lü, Russian Journal of Electrochemistry, 2006, Vol. 42, No 2, pp. 163-166. DOI: 10.1134/S1023193506020091.

12.Wang X., Yang N., Wan Q., Electrochimica acta, 2006, Vol. 52, No 1, pp. 361-368. DOI: 10.1016/j.electacta.2006.05.014.

13.Mohammad A., Amin A., Naushad M., ElDesoky G.E., Journal of thermal analysis and calorimetry, 2013, Vol. 111, No 1, pp. 831-838. DOI: 10.1007/s10973-011-2169-2.

14.Tian H.W., Li W.H., Wang D.P., Hou B.R., Acta Physico-Chimica Sinica, 2012, Vol.

Паршина Анна Валерьевна - д.х.н., доцент, кафедра аналитической химии, Воронежский государственный университет, Воронеж

Хабтемариам Гебремариам Зевельди - аспирант, кафедра аналитической химии, Воронежский государственный университет, Воронеж

Колганова Татьяна Сергеевна - к.х.н., преподаватель, кафедра аналитической химии, Воронежский государственный университет, Воронеж

Сафронова Екатерина Юрьевна - к.х.н., старший научный сотрудник, Лаборатория ионики функциональных материалов, Институт общей и неорганической химии имени Н.С. Курнакова РАН, Москва

Бобрешова Ольга Владимировна - д.х.н., профессор, главный научный сотрудник, кафедра аналитической химии, Воронежский государственный университет, Воронеж
28, No 1, pp. 137-145. DOI: 10.3866/PKU.WHXB201228137.

15. Vlasova N.N., Golovkova L.P., Stukalina N.G., Colloid Journal, 2015, Vol. 77, No 4, pp. 418-424. DOI: 10.1134/S1061933X15040201.

16.Penta N.K., Peethala B.C., Amanapu H.P., Melman A. et al., Colloids and Surfaces A: Physicochemical and Engineering Aspects, 2013, Vol. 429, pp. 67-73. DOI: 10.1016/j.colsurfa.2013.03.046.

17.Schnadt J., O'shea J.N., Patthey L., Schiessling J. et al., Surface science, 2003, Vol. 544, No 1, pp. 74-86. DOI: 10.1016/j.susc.2003.08.013.

18.Dancu A.C., Barabas R., Bogya E.S., Central European Journal of Chemistry, 2011, Vol. 9, No 4, pp. 660-669. DOI: 10.2478/s11532011-0057-z.

19. Altshuler H.N., Ostapova E.V., Malyshenko N.V., Altshuler O.H., Russian Chemical Bulletin, 2017, Vol. 66, No 10, pp. 1854-1859. DOI: $10.1007 / \mathrm{s} 11172-017-1957-7$.

20.Parshina A.V., Denisova T.S., Safronova E.Y., Karavanova Y.A. et al., Journal of Analytical chemistry, 2017, Vol. 72, No 12, pp. 12431250. DOI: $10.1134 / \mathrm{S} 1061934817120097$.

21.Mikheev A.G., Safronova E.Y., Yaroslavtsev A.B., Petroleum Chemistry, 2013, Vol. 53, No 7, pp. 504-510. DOI: 10.1134/S0965544113070104.

22.Niazi M.S.K., Mollin J., Bulletin of the Chemical Society of Japan, 1987, Vol. 60, No 7, pp. 2605-2610. DOI: https://doi.org/10.1246/ bcsj. 60.2605

23. Safronova E., Parshina A., Kolganova T., Bobreshova O. et al., Journal of Electroanalytical Chemistry, 2018, Vol. 816, pp. 21-29. DOI: 10.1016/j.jelechem.2018.03.028

Parshina Anna V. - Doctor of Chemical Sciences, docent, Department of Analytical Chemistry, Voronezh State University, Voronezh parshina ann@mail.ru

Habtemariam Gebremariam Z. - graduate student, Department of Analytical Chemistry, Voronezh State University, Voronezh

Kolganova Tatyana S. - PhD in Chemistry, lecturer, Department of Analytical Chemistry, Voronezh State University, Voronezh

Safronova Ekaterina Yu. - PhD in Chemistry, senior researcher, Laboratory of Ionics of Functional Materials, Kurnakov Institute of General and Inorganic Chemistry RAS, Moscow

Bobreshova Olga V. - Doctor of Chemical Sciences, professor, chief researcher, Department of Analytical Chemistry, Voronezh State University, Voronezh 